\title{
Influence of atmospheric conditions on the strength of unstabilized earthen constructions
}

\author{
Pierre Gerard ${ }^{1, a}$, Mohamed Mahdad ${ }^{1}$, Alexandre Robert ${ }^{1}$, Bertrand François ${ }^{1}$ \\ ${ }^{1}$ Université libre de Bruxelles (ULB), BATir Department, Laboratory of GeoMechanics (LGM), Brussels, Belgium
}

\begin{abstract}
Uniaxial compression tests and indirect tensile tests are performed on compacted clayey silt samples upon varying suctions in order to assess the influence of changes in the relative humidity conditions on the strength of unstabilized rammed earthen building materials. The results show that suction plays an important role on the strength of the material. Also the ability of the Belgian clayey silt to develop sufficient mechanical strength to be used as an unstabilized earthen construction material is demonstrated whatever the relative humidity conditions, excepted the fully water saturated state. The experimental data are interpreted in the context of unsaturated soil mechanics using the generalized effective stress concept. This constitutive framework allows defining a unified failure criterion predicting the strength of the earthen building material as a function of the environmental hygroscopic conditions.
\end{abstract}

\section{Introduction}

Earthen construction is an ancient technique that is experiencing a renascence today thanks to the hygrothermal regulation and the energy performance of this material and its potential for recycling. The material is locally available and the energy use for its manufacturing is very limited [1]. Soil is one of the most predominant materials on earth and can be considered universal to some extents that avoid dependency on importation.

In order to provide appropriate mechanical properties, the earthen materials must be installed in a proper way in order to optimize the density and the water content. Among different kinds of earthen constructions, rammed earth is the technique that consists in forming the wall by compacting moist soil between temporary forms. For "unstabilized" rammed earth, the system does not require any additional binder elements. A part of the cohesion is brought by the clayey materials in combination with the compaction process that provides the required density. In addition to the natural binding effect of the clayey material, capillary cohesion contributes also to the total strength of the materials [2,3]. However, after the construction, external rammed earth walls can be subject to changes in humidity and incident wetting from rainfall. Those modifications of environmental conditions induce continuous changes of the water retention conditions of the wall that affect the durability of the constructions.

Only a few studies focus directly on the impact of the change in relative humidity on the internal suction, and so on the strength of the wall. Unconfined compression tests have been performed on earthen materials samples air- dried to different target water contents [4], but the samples water content varied between $5.5 \%$ and $10.2 \%$, while the water content of an unstabilised rammed-earth construction subject to atmospheric conditions is generally lower (1-2\%) [5]. The unconfined strength of different soil samples (sand, clay) have been determined with a greater range of water content (from a wet state after manufacturing $\mathrm{w}=11 \%$ to a dry state in atmospheric conditions $\mathrm{w}=1-2 \%$ ) [6]. This study confirmed that suction plays an important role on the strength of the material, but highlighted also that a slight increase in moisture content of dry rammed-earth walls (water content not exceeding 4\%) due to rainfall or change of relative humidity in the atmosphere is not followed by a sudden drop in the wall strength.

This literature review reveals therefore first the scarcity of experimental procedure replicating the prevailing climatic conditions in different regions of the world, and quantifying the evolution of the unstabilized earthen materials strength with the atmospheric conditions. On the other hand no unified failure criterion has been formulated to characterize the effect of the suction and capillary cohesion on the strength of these materials.

The objective of the study is to evaluate the ability of a representative Belgian clayey silt to develop sufficient mechanical strength under variable relative humidity conditions to be used as an unstabilized rammed earthen building materials. To do so, the evolution of the strength as a function of the atmospheric relative humidity is characterized through uniaxial compression tests and indirect tensile tests. Then, a constitutive framework is proposed, able to predict the failure criterion of unstabilized rammed earthen materials, including the

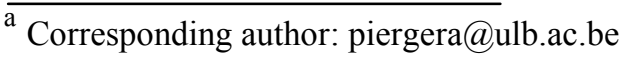


effect of capillary and intrinsic cohesion through the generalized effective stress approach for unsaturated soils.

\section{Materials}

The soil examined in this research is a clayey silt from the region of Marches-Les-Dames (Belgium). Its index properties are: liquid limit $\left(\mathrm{w}_{\mathrm{L}}\right)=32,5 \%$; plasticity index (IP) $=15 \%$. The clayey fraction represents $13 \%$, the silty one about $64 \%$ and the sandy one about $26 \%$. A series of recommendations on the grain-size distribution of soils particularly well adapted for earthen constructions has been published in [7]. Even though most of the guidelines for a suitable rammed earth particle size distribution recommend an inert aggregate fraction of gravel, the Marche-Les-Dames silt used in this study does not contain any gravel. Nevertheless the particle size distribution of the Marche-les-Dames silt approaches the one proposed by [8] and will show his relevance for earthen constructions. Those good properties are due to the spread grain size distribution of this natural clayey silt that induces a good interlocking of grains after compaction. The normal Proctor optimum water content $w$ is $15 \%$ and the normal Proctor optimum dry density $\rho_{d}$ is $18,40 \mathrm{kN} / \mathrm{m}^{3}$.

Even if the normal Proctor compaction test constitutes a widely used standard for the geotechnical earthworks, this method is generally not considered in the context of earthen materials. Indeed, the targeted properties of an earthen wall largely differ from the properties expected for geotechnical works. It is why another compaction process has been used in this research. The soil was dynamically compacted by sequentially ramming the soil in layers with a $2.5 \mathrm{~kg}$ Proctor hammer directly inside two kinds of mould: $36 \mathrm{~mm}$ in diameter and $72 \mathrm{~mm}$ in height for the uniaxial compression test (compacted in 3 layers) and $36 \mathrm{~mm}$ in diameter and $22 \mathrm{~mm}$ in height for indirect tensile test (compacted in 1 layer). The compaction of each layer was achieved until the handle of the hammer "rings" when dropped onto the compacted soil, which is considered as the indication of full compaction having being attained [7].

To determine the optimum initial water content samples were prepared at 8 different water contents (dried soil, 2\%, 4\%, 6\%,8\%, 10\%, 12\%, 14\%). The samples at a theoretical $0 \%$ and $2 \%$ of water contents were unusable as the samples became laminated and quickly dismantled at the limits of their compacted layers. The samples were then tested upon uniaxial compression loadings in order to evaluate their uniaxial compression strength (UCS) as a function of their water contents at compaction. For each compression, 3 to 4 samples were tested under unconfined compression for statistical consistency. It is to mention that the spreading of the strength never exceeds $10 \%$ of the mean value, which demonstrates a good reproducibility of the results. The obtained mean UCS is reported in Figure 1 together with the obtained dry density. For the sake of comparison, the mean UCS obtained on samples compacted at much lower dry density, $1732 \mathrm{~kg} / \mathrm{m}^{3}$, at different water contents are reported in Figure 2. This dry density is close to the optimum Proctor dry density of the soil.

First of all, the results show the relevance of the compaction method adapted for earthen construction. The process for earthen construction (Figure 1) provides much denser samples than the normal Proctor method with the consequence that the water content of rammed earth is lower that the normal Proctoroptimum water content. On the other hand the comparison between Figures 1 and 2 clearly demonstrates the drastic effect of soil density on its strength. This 'as-compacted UCS' reaches barely $1.4 \mathrm{MPa}$ upon a dry density of $1732 \mathrm{~kg} / \mathrm{m}^{3}$ at $6 \%$ of water content. On the contrary, when the soil is compacted until bouncing of the hammer, the samples develop an 'as-compacted UCS' that may reach $3.8 \mathrm{MPa}$ for a dry density of $2020 \mathrm{~kg} / \mathrm{m}^{3}$ when compacted at $8 \%$ of water content.

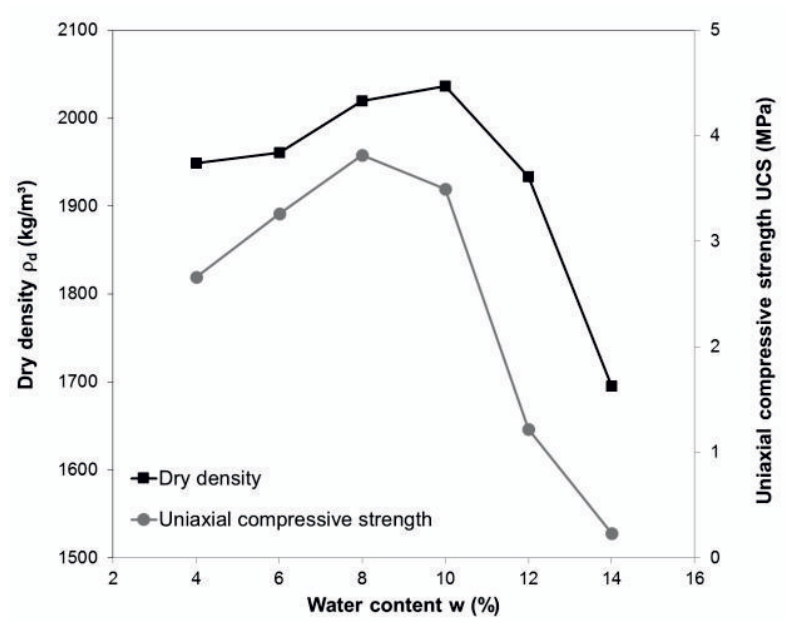

Figure 1. Uniaxial compressive strength and dry density vs. initial water content obtained on samples compacted with the process for earthen construction.

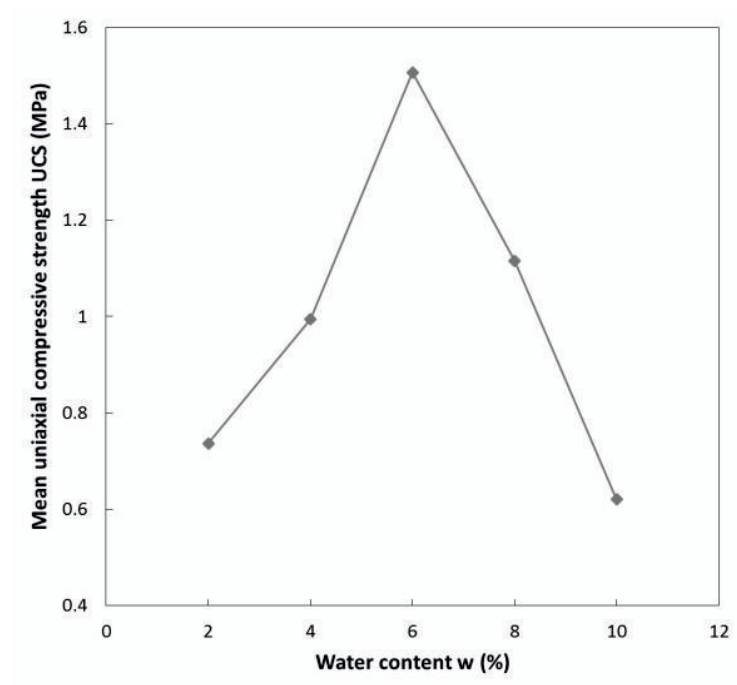

Figure 2. Mean uniaxial compressive strength according to the initial water content obtained on samples compacted at a dry density of $1732 \mathrm{~kg} / \mathrm{m}^{3}$.

In the next sections, the optimized conditions of compaction $\left(w=8 \%\right.$ and $\left.\rho_{d}=2000 \mathrm{~kg} / \mathrm{m}^{3}\right)$ have been selected to determine the effect of the hygroscopic 
variations on the strength. A target dry density slightly lower than the maximum density reached in Figure 1 was applied in order to take into account some possible losses of efficiency of the compaction process in in-situ conditions.

\section{Methods}

\subsection{Control of the suction}

To influence the relative humidity of air surrounding the sample, saturated saline solutions were used at a constant temperature of $20^{\circ} \mathrm{C}$ [9]: $\mathrm{K}_{2} \mathrm{SO}_{4}(R H=97 \%), \mathrm{KNO}_{3}$ $(R H=92 \%), \mathrm{KCl}(R H=85 \%), \mathrm{NaCl}(R H=75 \%)$. Also, $R H=40 \%$ was reached by placing the samples under ambient conditions in a room of the laboratory in which temperature and humidity remain constant. According to the relative humidity of the air, water exchanges occurring by vapour transfers between the sample and its surrounding induce a given suction at equilibrium within the sample (Kelvin's law):

$$
s=\frac{P_{W} R T}{M_{W}} \ln R H
$$

Also, a last hydraulic condition was obtained by sample saturation. A confining pressure of $200 \mathrm{kPa}$ was applied in the confining cell while a water pressure of $190 \mathrm{kPa}$ was applied on the lower porous stone. The saturation is reached when the flowrate of water injected in the sample through lower porous stone is equal to the flowrate of water measured through the upper porous stone. After dismantling the system, the degree of saturation is also checked by measuring and weighting the sample.

\subsection{Uniaxial compression test}

The scope of the uniaxial compression test is to determine the uniaxial compressive strength of soil samples with unrestricted horizontal deformation. The displacement of the piston was at $0.0667 \mathrm{~mm} / \mathrm{min}$ and the stress and strain were monitored every second. The uniaxial compressive strength $\sigma_{U C S}$ is calculated as:

$$
\sigma_{\text {UCS }}=\frac{F}{A_{c}}
$$

where $A_{c}$ is the equivalent section estimated under the assumption of constant volume of the sample during loading, and $F$ is the force applied by the piston.

It is worth to note that the size of the samples $(D=36$ $\mathrm{mm} ; H=72 \mathrm{~mm}$ ) is consistent with the recommendations on the geometry of the samples [10]. A slender ratio $(H / D)$ of 2 is indeed necessary for the determination of the uniaxial compressive strength of earthen materials. On the other hand Ciancio \& Gibbings have studied the influence of the sample size on its strength [11]. They tested several samples manufactured with different diameters and a constant slender ratio of 2 . While an inverse relationship between strength and specimen size is generally observed on concrete samples [12], they showed that the strength of earthen materials is not influenced by the size.

\subsection{Indirect tensile test}

In order to determine the uniaxial tensile strength of earthen materials, indirect tensile tests have been conducted. The test is valid for the materials exhibiting relative brittle failure which is the case for highly compacted earthen materials [13]. Under a compressive force $\mathrm{F}$ along its length $\mathrm{L}$, the minor principal stress is the horizontal stress, in tension, which corresponds to the tensile strength $\sigma_{\mathrm{t}}$ :

$$
\sigma_{3}=\sigma_{\mathrm{h}}=-\frac{2 F}{\pi d L}=\sigma_{\mathrm{t}}
$$

with $d$ the diameter of the sample.

\section{Experimental results}

\subsection{Water retention curve}

The amount of water stored in the specimen affects the capillary cohesion and has, in turn, a direct influence on the strength. So we focus first on the water retention curve.

Just after compaction, the initial water content is the imposed water content at compaction $\left(w_{0}=8 \%\right)$ while the suction $s$ has been evaluated at $2.4 \mathrm{MPa}$ by the filter paper method. This suction corresponds to the 'ascompacted' state of the material before any effect of the relative humidity of the atmosphere.

Then the soil suction was imposed through the control of relative humidity. Soil samples prepared at the two different dimensions and compacted according to the methodology described above were placed in desiccators with saturated salt solutions (or at ambient laboratory conditions for $\mathrm{RH}=40 \%$ ) and were weighted every day until reaching a constant weight. Figures 3 reports the water retention curve under the assumption of a constant volume of the sample upon drying.

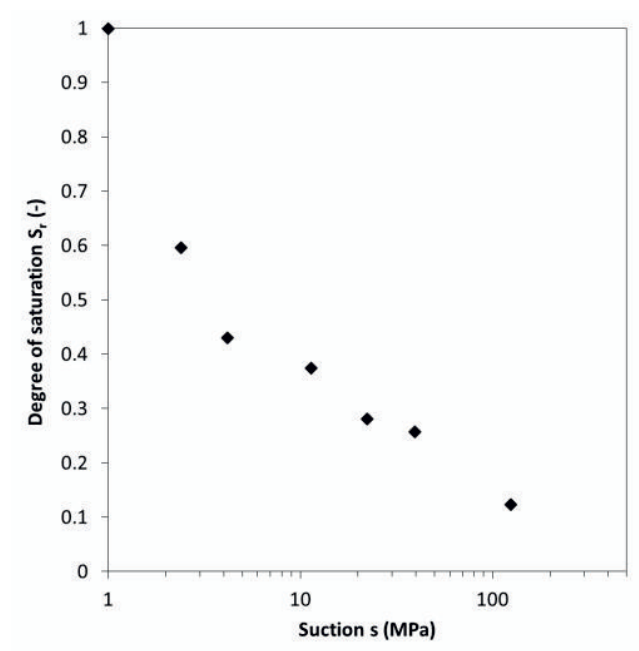

Figure 3. Retention curve of Marche-les-Dames silt 


\subsection{Uniaxial compressive strength}

The results (available in details in [14]) exhibit the following trends:

- The UCS increases with suction: dryer is the soil and higher is the strength.

- However, in the same time, the brittleness also increases with suction: the material is less and less ductile when the amount of water in the soil decreases.

- Upon saturated conditions, the strength is almost zero while it is very ductile.

Figure 4 summarizes the obtained UCS as a function of the applied suction. Suction is reported on a logarithmic scale. Saturated conditions (for which suction is almost zero) were arbitrary linked to suction of $1 \mathrm{MPa}$, for the convenience of the representation. Excepted for the results at $4.17 \mathrm{MPa}$ of suction, a logarithmic regression curve provides a good estimation of the obtained UCS. The points out of the trend at $4.17 \mathrm{MPa}(R H=97 \%)$ can probably be explained because of the precision of the relative humidity technique at low suctions. This is a well-known drawback of this technique which is not adequate to apply low suctions. A small error in the imposed relative humidity induces a large approximation in the imposed suction (e.g. 1\% of relative uncertainty on $R H$ leads to $1.38 \mathrm{MPa}$ of absolute uncertainty for the suction) [9].

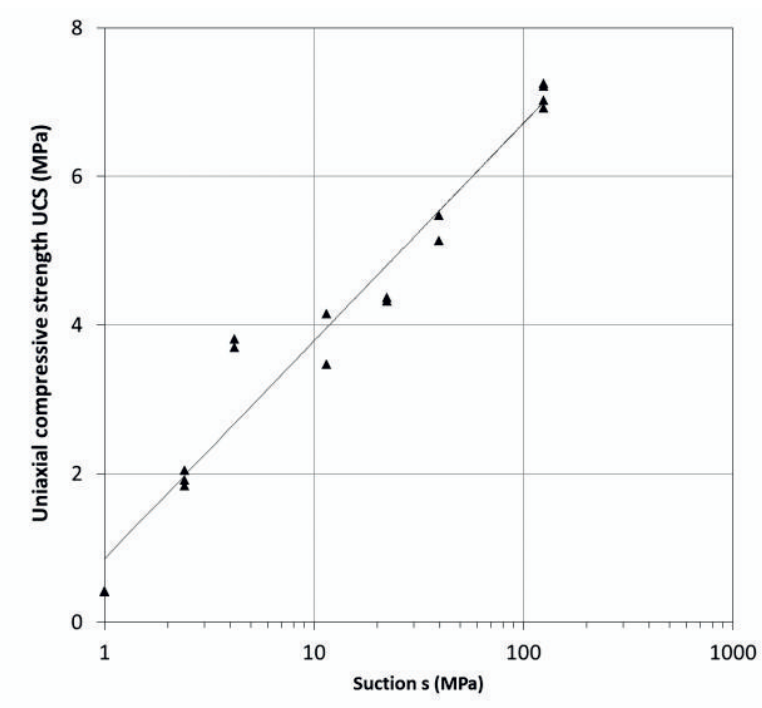

Figure 4. Uniaxial compressive strength according to the imposed suction.

\subsection{Tensile strength}

The ultimate tensile strength is reported in Figure 5 according to the imposed suction. Again, logarithmic regression curve provide a good estimation of the evolution of the strength as a function of suction, except for the points at $4.17 \mathrm{MPa}(R H=97 \%)$, for the same reasons than exposed before.

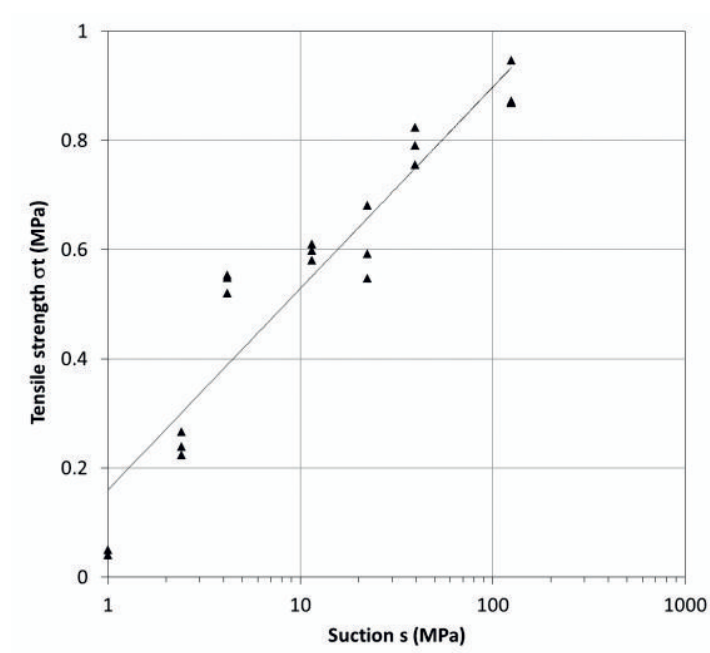

Figure 5. Tensile strength according to the imposed suction.

\section{Constitutive framework}

The objective of this section is to find an expression of generalized effective stress that permits to obtain a unique failure criterion that is unaffected by suction and degree of saturation, when it is expressed in this new stress reference. In other words, the dependency of the water retention conditions on the strength is directly included in the stress definition and is not explicitly taken into account in the expression of the failure criterion. To do so, it is proposed to start from the general expression of generalized effective stress $\sigma^{b}{ }_{i j}$ as originally proposed by Bishop [15]:

$$
\sigma^{s} i j=\sigma_{i j}+\chi s \delta_{i j}
$$

where $\chi$, called the effective stress parameter, varies with the degree of saturation $[15,16]$, from zero for dry soil to unity for fully saturated conditions. $\sigma_{i j}$ is the total stress tensor and $\delta_{i j}$ is the Kronecker symbol. This Bishop's effective stress implies that the mechanical response is directly linked to the water retention behavior through the parameter $\chi$. Consequently, generalized effective stress state experienced by specimen during both uniaxial compression tests and indirect tensile tests can be reported in the Mohr plane with Mohr circles which are shifted to the right by an amount equal to $\chi s$. The objective is to find a suitable expression of $\chi$ as a function of the degree of saturation $S_{r}$ that permits a shift of the obtained Mohr circles at failure that fulfills a unique failure criterion.

The first step towards the definition of a unified failure criterion for the studied rammed earth material consists in the determination of the intrinsic strength parameters, friction angle $\varphi$ and cohesion $c$. To do so, 4 consolidated and undrained (CU) triaxial tests have been performed on saturated samples at different confining pressures $\sigma_{3}(50,100,200$ and $300 \mathrm{kPa})$, with measurement of the pore pressures evolution during shearing. Considering the maximum ratio $\sigma^{\prime}{ }_{2} / \sigma^{s}{ }_{1}$ as the ultimate stress state, this leads to a friction angle $\varphi=36.5^{\circ}$ and a cohesion $c=6.2 \mathrm{kPa}$ (more details in [14]). 
Secondly, when the intrinsic criterion is defined, the purpose being to obtain an unique failure criterion, the objective is to find the value of $\chi$, expressed as a function of $S_{r}$, that allows to translate horizontally the corresponding Mohr circle at the ultimate stress state expressed in total stress on the failure criterion. The horizontal distance between the Mohr circle expressed in total stress and the failure criterion is the value $\chi s$. Knowing that $\sigma_{3}^{\prime}$ is expressed as $\sigma^{s}{ }_{\mathrm{a}}=\chi s$ for the uniaxial compression test and $\sigma_{a}^{s}=\sigma_{h}+\chi s$ for the indirect tensile tests, the value $\chi s$ can be obtained geometrically from (Figure 6):

$$
\sigma_{\mathrm{a}}^{*}=\frac{R-c \cos \varphi}{\sin \varphi}-R
$$

with $R=\left(\sigma_{1}-\sigma_{3}\right) / 2$

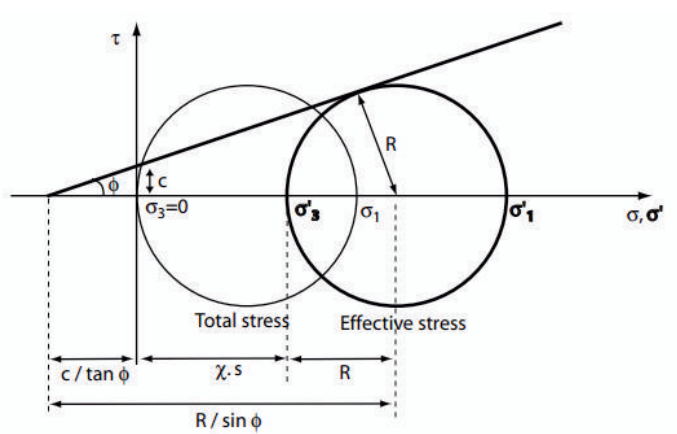

Figure 6. Mohr circle at failure for uniaxial compression test expressed in total stress and effective stress.

This method can be applied to every single test result to obtain one value of $\chi$ per test. Because for each test, the value of the degree of saturation of the sample is measured, it is possible to obtain a set of points in the $\chi$ $S_{r}$ plane, as reported in Figure 7. It is then decided to find a relation in the form:

$$
\chi=\left(S_{y}\right)^{\alpha} \Rightarrow \log \chi=\alpha \log S_{y}
$$

where $\alpha$ is a material parameter which is the slope of the regression line in the plane $\log \chi-\log S_{r}$ reported in Figure 8 .

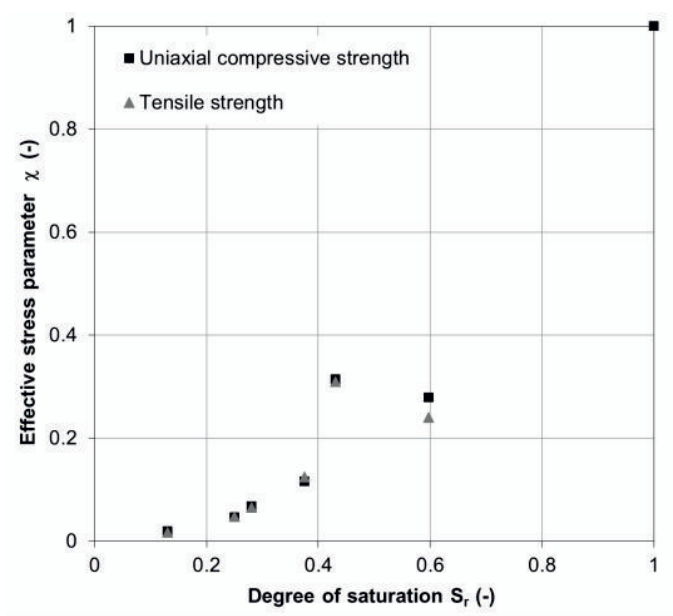

Figure 7. Degree of saturation vs. effective stress parameter $\chi$ from both uniaxial compressive strength and tensile strength.
In such a way, we find $\alpha=2.08$. The obtained relationship between $\chi$ and $S_{r}$ is compared, in Figure 9, with other relationships proposed for several soils and summarized by Zerhouni [17]. Our relationship is relatively similar to the ones obtained by Zerhouni [17] on the Sterrebeek silt and by Jennings and Burland [18] on a silty clay. This is totally consistent because those materials have rheological properties very similar to the ones of the soil tested in this study. Moreover, the obtained trend follows the conceptual model of Alonso et al. [19] with a limited increase of the effective stress parameter for low degree of saturation while the increase is more significant for higher degree of saturation. The compaction process at relatively low water content induces a double structure to the material with two characteristic sizes of pores (large pores between aggregates and small pores inside aggregates). Consequently, upon low degree of saturation, the water is essentially stored inside the aggregates and this "intraaggregate" water does not contribute to the macroscopic stress. Upon higher degree of saturation, water floods the "inter-aggregate" voids which contributes more to the increase of the internal stress.

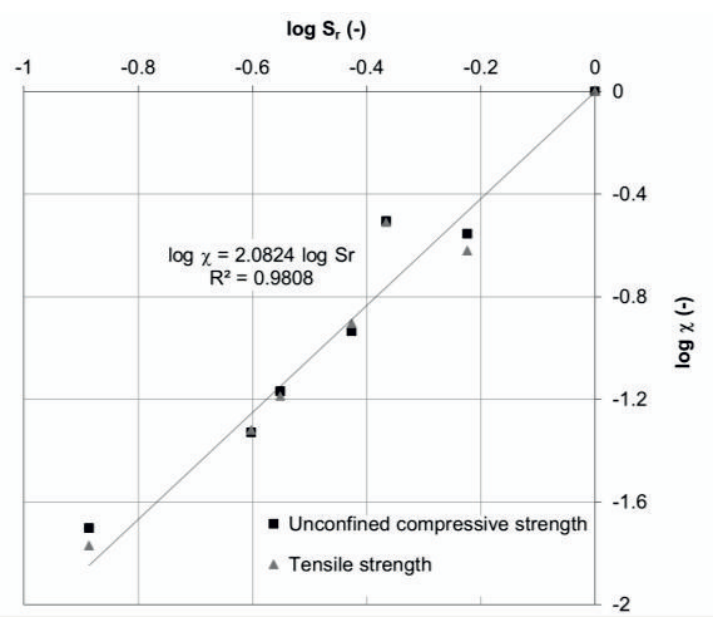

Figure 8. Degree of saturation vs. effective stress parameter $\chi$ from both uniaxial compressive strength and tensile strength in logarithmic plane.

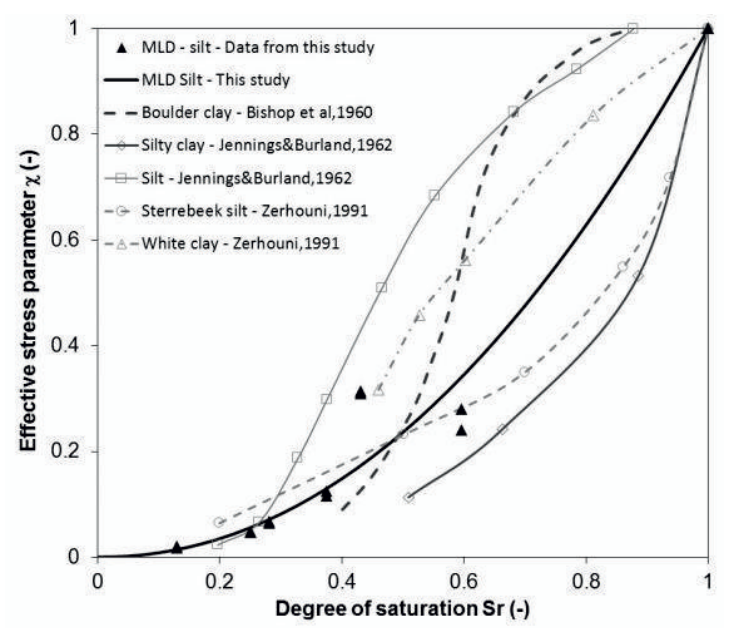

Figure 9. Effective stress parameter according to the degree of saturation for different soils. 
Finally, the set of Mohr circles at failure obtained from uniaxial compression tests and indirect tensile tests are reported in Figure 10 and 11 using the generalized effective stress reference defined previously:

$$
\sigma^{s}{ }_{i j}=\sigma_{i j}+S_{y}^{2.08} s \delta_{i j}
$$

As expected, the obtained Mohr circles at failure fulfill a unique failure criterion based on the cohesion and the friction angle deduced from triaxial tests under saturated conditions. It is worth mentioning that both uniaxial compression and indirect tensile tests upon saturated conditions do not fit well the failure criterion. It is explained by the probable undrained conditions of the saturated samples under such loadings that makes the interpretation in effective stress inappropriate.

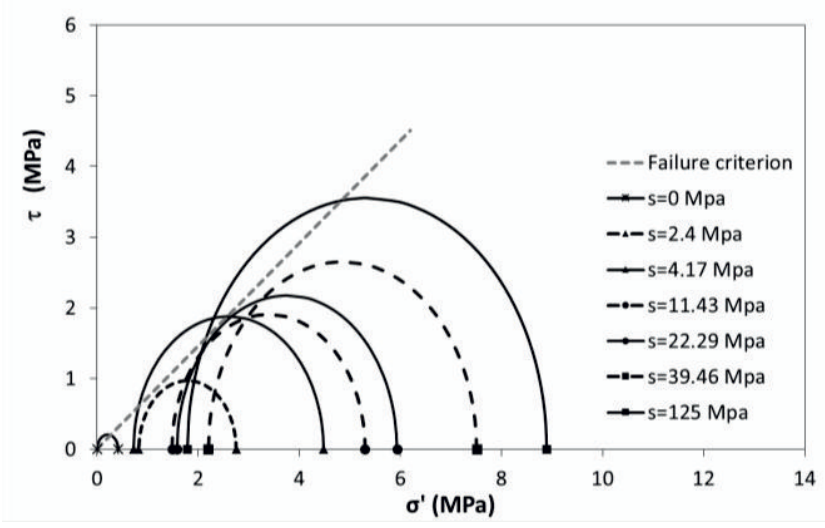

Figure 10. Mohr circles at failure expressed in terms of generalized effective stress for uniaxial compression tests at different initial suctions.

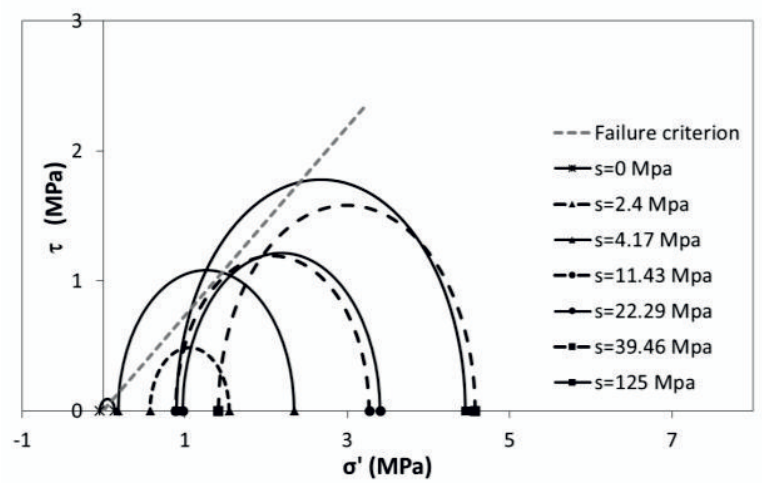

Figure 11. Mohr circles at failure expressed in terms of generalized effective stress for indirect tensile tests at different initial suctions.

\section{Conclusions}

The tensile and compressive strengths of unstabilized rammed earthen building materials are strongly affected, not only by the density of the material, but also by the relative humidity conditions. In this study, the hygroscopic behavior is taken into account through the water retention curve that relates the degree of saturation to the suction. This curve has a significant impact on the internal stress state of the material which, in turn, affects its mechanical behavior. We demonstrated that a framework based on the concepts of unsaturated soil mechanics using a generalized effective stress is particularly well-suited to provide a unified failure criterion including the effect of the suction inside the stress state. Consequently, suction provides additional strength to the material by mobilizing internal friction between grains. Moreover, we demonstrate the uniqueness of the obtained failure criterion in the sense that it gathers the strengths obtained from uniaxial compression tests and indirect tensile test into a single criterion. A practical outcome of this unified failure criterion is the estimation of the rammed earth

\section{References}

1. J.C. Morel, A. Mesbah , M. Oggero, P. Walker, Build Environ 36 (2001)

2. D.G. Fredlund, H. Rahardjo, Soil Mechanics for Unsaturated Soils (Wiley, 1993)

3. C. Beckett, C. Augarde, Unsaturated soils: Research and Applications (C. Mancuso, C. Jommi, F. D’Onza (Eds.), Springer, 2012)

4. P.A. Jaquin, C.E. Augarde, D. Gallipoli, D.G. Toll, Geotechnique 55, 5 (2009)

5. Q.B. Bui, J.C. Morel, S. Hans, N. Meunier, Mater Struct 42, 8 (2009)

6. Q.B. Bui, J.C. Morel, S. Hans, P. Walker, Constr Build Mater 54 (2014)

7. P. Walker, R. Keable, J. Martin, V. Maniatidis, Rammed Earth: Design and Construction Guidelines (BRE Bookshop, Watford, 2005)

8. P.J. Alley, New Zeal Eng 3, 6 (1948)

9. P. Delage, M.D. Howat, Y.J. Cui, Eng Geol 50 (1998)

10. J.E. Aubert, A. Fabbri, J.C. Morel, P. Maillard, Constr Build Mater 47 (2013)

11. D. Ciancio, J. Gibbings, Constr Build Mater 28 (2012)

12. J.H. Bungey, S.G. Millard, Testing of concrete in structures (Taylor \& Francis, 1996)

13. D. Li, L.N.Y. Wong, Rock Mech Rock Eng 46, 2 (2013)

14. P. Gerard, M. Mahdad, A. Robert McCormack, B. François, Constr Build Mat 95 (2015)

15. A.W. Bishop, Ukeblad 39 (1959)

16. L. Laloui, M. Nuth, Comput Geotech 36, 1-2 (2009)

17. M.I. Zerhouni, Rôle de la pression interstitielle négative dans le comportement des sols - application au calcul des routes ( $\mathrm{PhD}$ Thesis. Ecole Centrale Paris, 1991).

18. J.E.B. Jennings, J.B. Burland, Geotechnique 12 (1962)

19. E.E. Alonso, N.M. Pinyol, A. Gens, Geotechnique 63, 6 (2013) 